\title{
Evolution of the Parisian urban climate under a global changing climate
}

\author{
Aude Lemonsu • Raphaëlle Kounkou-Arnaud • \\ Julien Desplat · Jean-Luc Salagnac · Valéry Masson
}

Received: 6 October 2010 / Accepted: 6 June 2012 / Published online: 5 July 2012

(C) The Author(s) 2012. This article is published with open access at Springerlink.com

\begin{abstract}
The evolution of the Parisian urban climate under a changing climate is analyzed from long-term offline numerical integrations including a specific urban parameterization. This system is forced by meteorological conditions based on presentclimate reanalyses (1970-2007), and climate projections (2071-2099) provided by global climate model simulations following two emission scenarios (A1B and A2). This study aims at quantifying the impact of climate change on air temperature within the city and in the surroundings. A systematic increase of 2-meter air temperature is found. In average according to the two scenarios, it reaches $+2.0 / 2.4^{\circ} \mathrm{C}$ in winter and $+3.5 / 5.0^{\circ} \mathrm{C}$ in summer for the minimum and maximum daily temperatures, respectively. During summer, the warming trend is more pronounced in the surrounding countryside than in Paris and suburbs due to the soil dryness. As a result, a substantial decrease of the strong urban heat islands is noted at nighttime, and numerous events with negative urban heat islands appear at daytime. Finally, a $30 \%$ decrease of the heating degree days is quantified in winter between present and future climates. Inversely, the summertime cooling degree days significantly increase in future climate whereas they are negligible in present climate. However, in terms of accumulated degree days, the increase of the demand in cooling remains smaller than the decrease of the demand in heating.
\end{abstract}

\footnotetext{
A. Lemonsu $(\varangle) \cdot$ V. Masson

Groupe d'étude de l'Atmosphère MÉtéorologique, CNRS/Météo-France, GMME/TURBAU, 42 Avenue Gaspard Coriolis, 31057 Toulouse Cedex, France e-mail: aude.lemonsu@meteo.fr

R. Kounkou-Arnaud · J. Desplat

Direction Interrégionale Ile-de-France/Centre, Météo-France, Paris, France

J.-L. Salagnac

Centre Scientifique et Technique du Bâtiment, Vincennes, France
} 


\section{Introduction}

Cities are particularly concerned by climate change. Firstly, by concentrating the majority of human activities, they strongly contribute to the greenhouse gases emissions and consequently to the global warming that is already observed (IPCC 2007) and that will become particularly significant beyond 2070. On the other hand, it is expected that these global trends will be more marked at the city scale due to the urban processes such as urban heat islands (UHIs). Moreover, several studies already displayed a significant urban signal that tends to reinforce the increase trends detected in the temperature historical time-series (Jones et al. 1990; Wilby 2003; Gaffin et al. 2008; Fujibe 2011). During future decades, the complex interactions between the effects of global change at regional scale and the evolution of cities themselves (coupling urban growth and increase in population) will probably lead to a deep change of urban climate. Consequences may be various (Rosenzweig and Solecki 2001), in terms of managment of infrastructures, water resources, pollution, bioclimatic comfort and public health, energy demand and so on.

It is quite challenging to take into account the multiple processes which come at stake in the study of the impact of climate change at the city scale. Recently, some future urban climate projections have been produced in order to tackle different issues such as frequency of heat days (García Cueto et al. 2010; Früh et al. 2011), UHIs (Wilby 2003), air pollution (Athanassiadou et al. 2010), urban water supply (O'Hara and Georgakakos 2008), energy consumption (Amato et al. 2005; Franco and Sanstad 2008), or economic impacts (Hallegatte et al. 2007). Most of these works produce local-scale projections by applying statistical downscaling techniques to global climate model's (GCM) outputs, and evaluate the impacts in a simple way without modeling the city itself. Früh et al. (2011) propose a more sophisticated method that firstly projects the global climate at the regional scale according to both dynamical and statistical downscaling techniques, and then simulates the urban climate by using the specific urban climate model MUKLIMO_3.

Our study that is part of the EPICEA project (French acronym for pluridisciplinary study of the impacts of climate change at the scale of Paris region-Desplat et al. 2009) is based on a similar approach. Long-term numerical integrations of few tens of years are conducted over Paris area by using a land-surface modelling system including the Town Energy Balance (TEB) urban canopy model (Masson 2000) that is able to simulate the urban climate at the city and neighborhood scales. This system is forced by meteorological conditions based on present-climate reanalyses (1971-2006) and climate projections (2072-2098) provided by GCM simulations. This study aims at quantifying the impact of climate change mainly on street-level air temperature within the city and in the surroundings.

\section{Land-surface modeling system}

In order to run long-term experiments, the urban climate simulations are performed in offline mode by using the SURFEX land surface modeling system (Salgado and Le Moigne 2010) that includes the Interaction between Soil, Biosphere, and Atmosphere (ISBA) model (Noilhan and Planton 1989) for the natural covers and the Town Energy Balance (TEB) urban canopy model (Masson 2000) for built-up covers. 

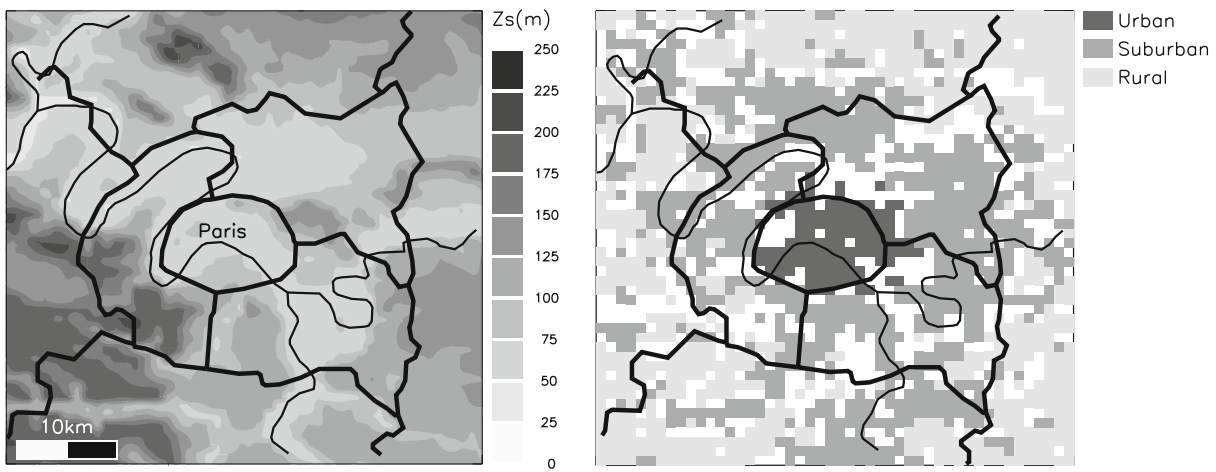

Fig. 1 Modeling domain. Left: topography with boundaries of administrative counties (thick black lines) and rivers (thin black lines). Right: grid points classified as urban dense areas, suburban areas, and rural areas. White areas correspond to the grid points with mixed land-cover types

The system is run over a domain of $48 \mathrm{~km} \times 48 \mathrm{~km}$ that covers the large Paris region with a 1-km spatial resolution (Fig. 1, left). The land-use and land-cover types are defined by the CORINE land-cover classification (Heymann et al. 1993) available at the same resolution. The urban areas are mainly described by the "urban dense areas" class that covers Paris intra muros and the "residential areas" class located all around Paris. The main types of vegetation that surround the agglomeration are composed of crops, and broad-leaves forests.

In case of offline simulations, the effects of horizontal advection are not explicitly considered. A set of atmospheric forcing is built and provided to SURFEX over two study periods in present and future climates starting from the corrected and downscaled climatic scenarios presented in the next section.

\section{Climatic forcing}

\subsection{Reference historical dataset}

A 50-year reference atmospheric retrospective dataset (1958-2008) is available over France at high temporal and spatial resolution (hourly, $8 \mathrm{~km}$ ). These reanalyses were produced with the SAFRAN system (Durand et al. 1993; Durand et al. 1999) by combining European Centre for Medium-Range Weather Forecasts (ECMWF) global reanalysis archives and all available surface observations from the MétéoFrance climatological database. For the present study, these SAFRAN reanalyses are used in the evaluation stage of the SURFEX simulation in present climate, presented in Section 4.

\subsection{Climatic scenarios}

Climatic scenarios were retrieved from the RExHySS French project (Ducharne et al. 2009). Climate projections were produced with the variable-resolution ARPEGEClimat (Gibelin and Déqué 2003) GCM from Météo-France that covers Western 
Europe with a 50-km spatial resolution. Atmospheric simulations were performed using the A2 and A1B emission scenarios (IPCC 2000).

The combination of a dynamical downscaling with a quantile-quantile $(q-q)$ correction method (Déqué 2007) was applied to reduce the GCM systematical errors. For the IMFREX project (Déqué 2005), the correction functions were initially calculated independently per season and per variables (for daily precipitation, minimum and maximum temperatures) by comparing the distribution functions of observations and simulations (see Fig. 2 from Déqué 2007, which presents the q-q plots obtained for Paris area). By assuming the stationarity of model errors with time, the same functions were applied to adjust GCM outputs in future climate. This method was refined for the RExHySS project (Déqué 2009, for details) by doing a normalized principal component analysis which uses the seven observed variables provided by the SAFRAN reanalyses and which determines correction functions depending on weather types.

\subsection{Adapation to the urban scale}

The meteorological conditions coming from the downscaling of the ARPEGE runs are initially available at $2 \mathrm{~m}$ above ground level (agl) for temperature and humidity, and $10 \mathrm{~m}$ agl for wind. For our study, we need to build new forcing at $60 \mathrm{~m}$ agl (that corresponds to twice the height of the tallest buildings in Paris) in order to force SURFEX above the roughness sublayer. A simple method based on successive simulations performed with SURFEX enables to adjust in an iterative way the meteorological conditions at $60 \mathrm{~m}$ agl by comparing the near-surface parameters obtained for each SURFEX simulation with reference conditions (provided by the ARPEGE runs).

Each iteration is composed of three stages (Fig. 2): (1) the definition of the meteorological forcings in temperature, humidity, and wind at $60 \mathrm{~m}$ agl with a 8$\mathrm{km}$ horizontal resolution, referred to as $V_{\mathrm{frc}(60 \mathrm{~m})}$; (2) the SURFEX simulation which provides the near-surface diagnostics (2-m air temperature and humidity, and 10m wind speed) referred to as $V_{\text {sfx(surf) }}$; (3) the model error for each parameter $V_{\text {err(surf) }}$ which is calculated as the bias between $V_{\text {sfx(surf) }}$ and the reference variables provided by the downscaling of the ARPEGE runs $V_{\text {ref(surf) }}$. For the first iteration, the reference variables are directly applied as forcing for SURFEX at $60 \mathrm{~m}$ agl, i.e. $V_{\text {frcl }(60 \mathrm{~m})}=V_{\text {ref(surf) }}$ in this case. The near-surface model biases are calculated at each grid point of the domain with a 6-hour timestep according to $V_{\text {err1(surf) }}=$ $V_{\text {sfx1(surf) }}-V_{\text {ref(surf) }}$. The biases are assumed to be conservative between the

Fig. 2 Diagram describing the methodology for providing meteorological conditions at a prescribed vertical level, chosen as forcing level for SURFEX simulations. For the first iteration,

$V_{\mathrm{frc}(60 \mathrm{~m})}^{\mathrm{n}-1}=V_{\text {ref(surf) }}$ and

$V_{\text {err(surf) }}^{\mathrm{n}-1}=0$

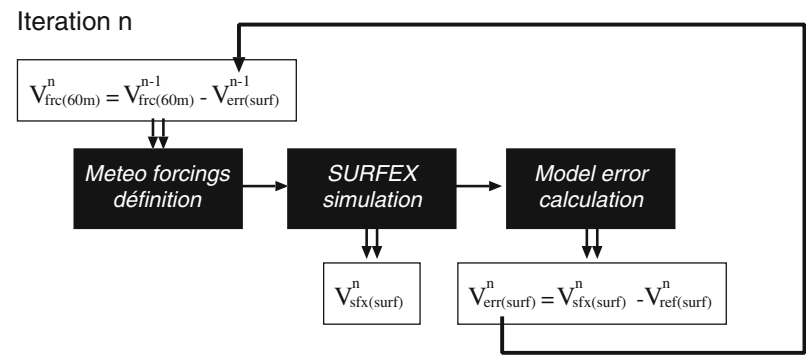



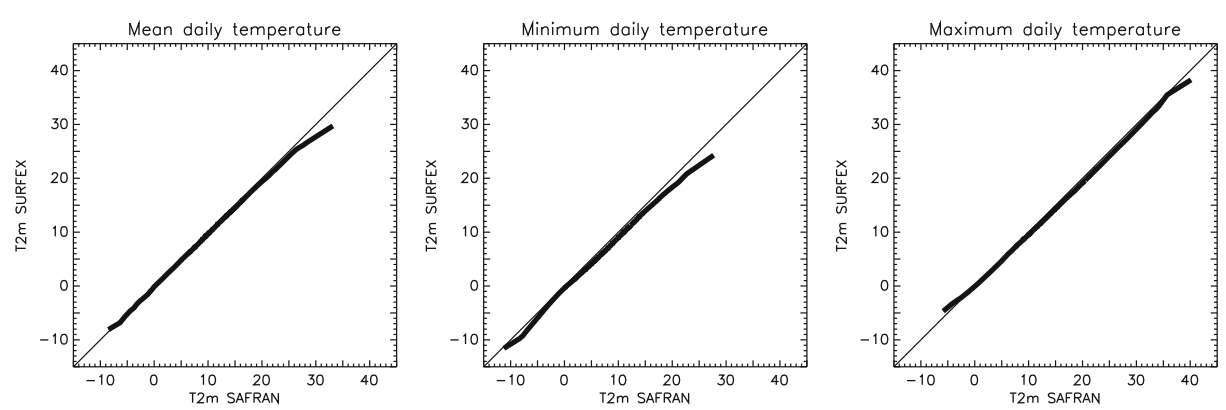

Fig. 3 Quantile-quantile comparison between 2-m air temperature from SAFRAN reanalyses and from SURFEX over the present period and for all the domain. The model outputs only take into account the mesh fractions with vegetation and are aggregated at the same spatial resolution than SAFRAN reanalyses

near-surface and 60-m forcing levels. The new forcings for the next iteration are then corrected according to $V_{\text {frc2 }(60 \mathrm{~m})}=V_{\text {frc1 }(60 \mathrm{~m})}-V_{\text {err1(surf), and so on. The method is }}$ applied on the basis of three iterations because a preliminary sensitivity test showed that a greater number of iterations does not improve the results significantly.

\section{Evaluation of the model over the present period}

The SURFEX model is run at a 1-km spatial resolution continuously over a control period in present climate (August 1st 1970-July 31st 2007) for which it provides the 1-km fields of daily minimum, maximum, and mean 2-m air temperatures $\left(T_{N}\right.$, $\left.T_{X}, T_{A V G}\right)$. Figure 3 presents the comparison according to the $q-q$ method between the $8-\mathrm{km}$ resolution SAFRAN reanalyses (that do not account for urban effects) and the 2-m air temperature simulated by SURFEX over the mesh fractions with vegetation only and aggregated at the same spatial resolution than SAFRAN. The model compares correctly against observation for $T_{A V G}, T_{N}$, and $T_{X}$. A slight underestimation of the warm extremes however must be noted, more important for $T_{A V G}$ and $T_{N}$ (up about $3^{\circ} \mathrm{C}$ ) than for $T_{X}$. The cold extremes are well simulated.

\section{Evolution of temperature over Paris with climate change}

\subsection{General trends}

The daily minimum and maximum 2-m air temperatures are averaged for the main CORINE land-cover classes of the domain : "urban dense areas", "residential areas", and "crops"/"broad-leaves forests" associated with three different urbanization degrees that are referred to as urban, suburban, and rural areas afterwards (see Fig. 1, right). These temperatures $T_{N}$ and $T_{X}$ are then averaged over various time periods: complete present period (1971-2006), and 15-year subperiods (1971-1985, 1982-1996, 1992-2006), as well as complete future period (2072-2098), and 15-year subperiods (2072-2086, 2084-2098).The results are summarized in Table 1.

In accordance with the global warming trends, temperatures simulated in future climate are significantly warmer than in present climate, and more particularly for 
Table 1 Yearly 2-m air temperature (Unit: ${ }^{\circ} \mathrm{C}$ ) averaged for urban, suburban, and rural areas over present (36 years) and future (28 years) climates

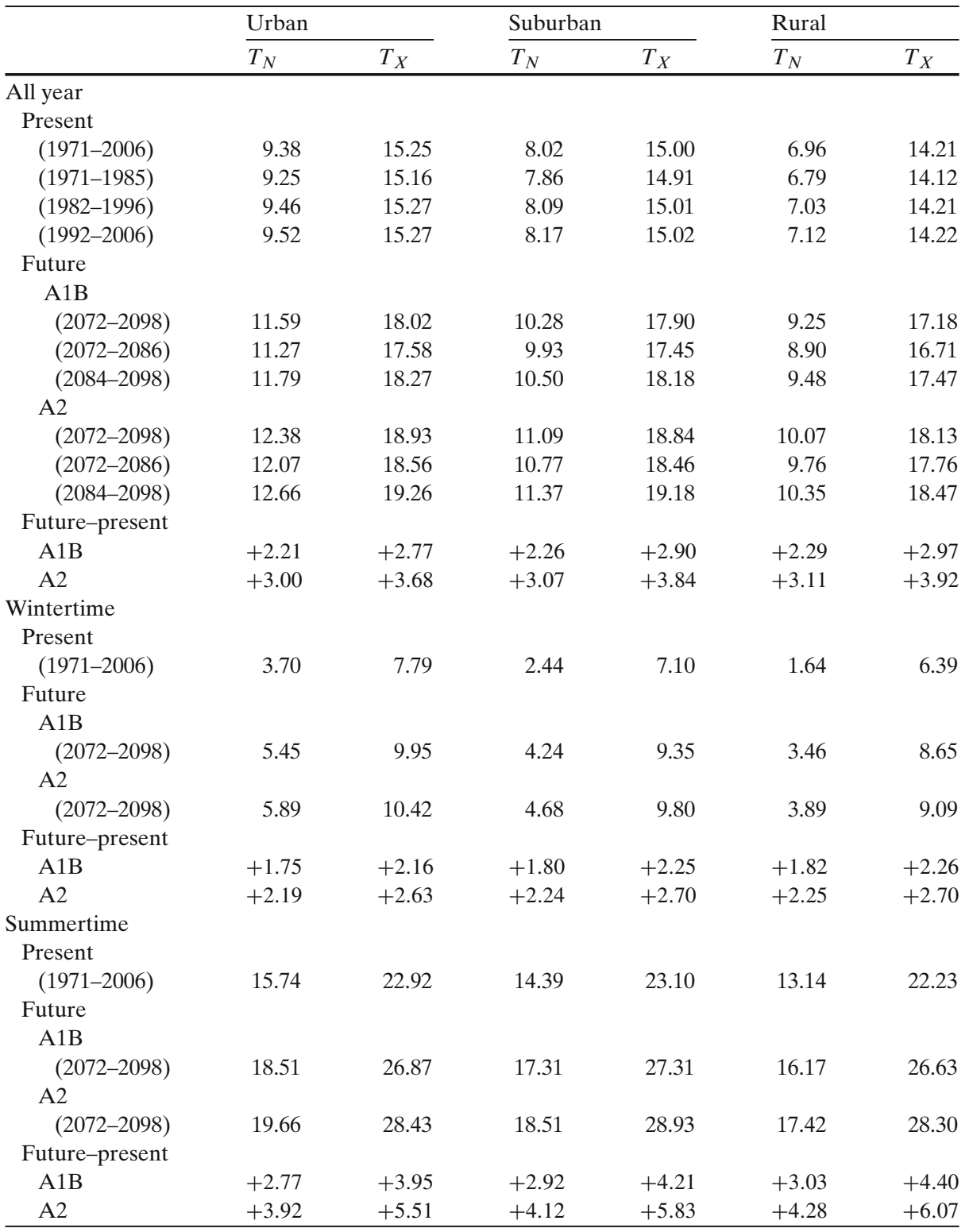

the most pessimistic scenario (A2) associated with larger greenhouse gases emissions. The increase in temperature is appreciably stronger for rural areas than for suburban and urban areas for both $T_{N}$ and $T_{X}$ (Table 1), and for both scenarios. The higher increase in temperature is noted for $T_{X}$ with $\mathrm{A} 2$ scenario; it reaches $+3.92^{\circ} \mathrm{C}$ in the countryside against $+3.68^{\circ} \mathrm{C}$ in Paris. These trends that are mainly driven by summer conditions will be discussed more in detail in Section 5.3. 
Finally, a intrinsic trend of temperature increase can be noted during present and future periods. Warming trends of about +0.14 and $+0.09^{\circ} \mathrm{C} /$ decade are evaluated over present climate for $T_{N}$ and $T_{X}$, respectively, in average over all the domain. These trends intensify in the future, more particularly for daytime temperature; they reach in average +0.35 and $+0.46^{\circ} \mathrm{C} /$ decade for $T_{N}$ and $T_{X}$, respectively, with A1B scenario, and +0.46 and $+0.56^{\circ} \mathrm{C} /$ decade for $\mathrm{A} 2$ scenario. The analysis by 15 -year subperiods indicates an acceleration of the warming after 2085.

\subsection{Wintertime temperature}

The results obtained for the wintertime temperatures are summarized in Table 1. A systematic increase of air temperature between present and future climates is displayed. It is more important for $T_{X}$ than $T_{N}$ (about $+2.4 v s+2.0^{\circ} \mathrm{C}$ in average over both scenarios). The comparison in temperature for the three land-cover classes indicates that the trends are comparable for $T_{N}$ whatever the degree of urbanization, whereas $T_{X}$ increases slightly more in suburban and rural areas than in urban areas.

The variability and impact of climate change can also be evaluated through standardized indices that are nowadays widely used (Klein Tank and Konnen 2003; Alexander et al. 2006; Klein Tank and Zwiers 2009; Van den Besselaar et al. 2010). Climate indices for wintertime temperatures are cold days and very colds days (days with $T_{N} \leq-5$ and $-10^{\circ} \mathrm{C}$, respectively), frost days $\left(T_{N} \leq 0^{\circ} \mathrm{C}\right)$, and ice days $\left(T_{X} \leq 0^{\circ} \mathrm{C}\right)$. This ensemble of cold indices decreases significantly in the future in accordance with the general trend presented by Déqué (2007) who notices that the number of cold days in France becomes negligible at the end of this century. In rural areas, from more than 6 cold days per year in present time this number decreases to about 1 day per year in the future (Fig. 4a). In the same way, the number of very cold days which is already very small in present time becomes 0 in the future (Fig. 4b). The number of frost days remains significant (about 16-20 days per year according to the scenario) but decreases of 50-60\% in comparison with present climate (Fig. 4c). Finally, the number of ice days decreases from 6 to 1-2 days per year whatever the scenario (Fig. 4d).

The distributions of the number of days for each indice are similar with regards to urbanization degree: cold indices are more important in rural areas than in suburban and urban areas. The situations of cold days simulated in urban areas become extremely rare with a return period of more than 5 years (Fig. 4a). It is the same for the frost and ice days which are about 3.5 and 5.0 times less numerous in urban than rural areas, respectively, in future climate (Fig. 4c and d). These differences in the indices calculated for urban and rural areas are also noticed in present climate but they are emphasized at the end of the 21 st century. This indicates first the occurrence of warmer winters in the future with less extreme cold temperatures than in present time, and second the conservation of wintertime UHIs in both scenarios.

\subsection{Summertime temperature}

The increase in air temperature is more significant during summertime (Table 1) than during wintertime. In average over both scenarios, $T_{N}$ and $T_{X}$ increase by +3.5 and $+5.0^{\circ} \mathrm{C}$, respectively, in rural areas between present and future periods. To corroborate these results, the same trends are calculated over the Paris region 
a. Cold days
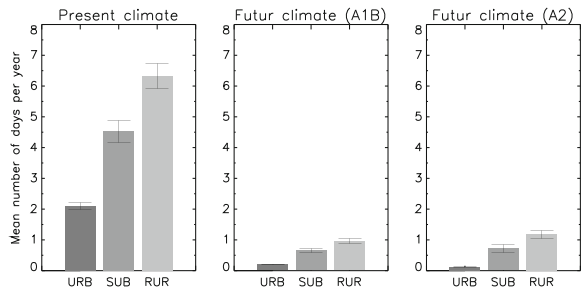

c. Frost days
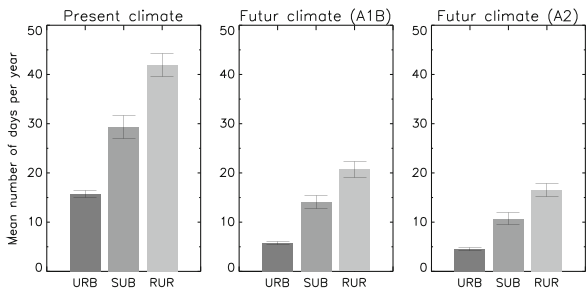

e. Very hot days
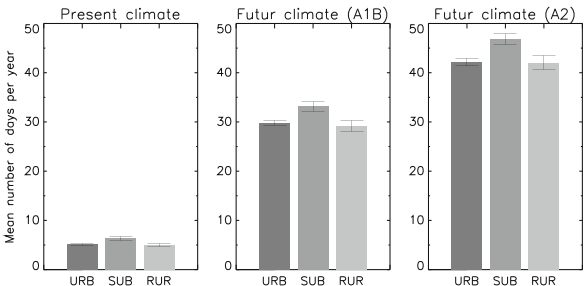

g. Tropical night
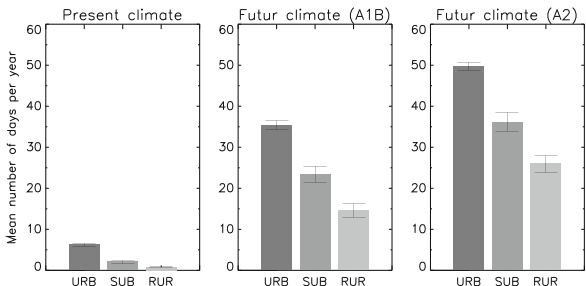

b. Very cold days
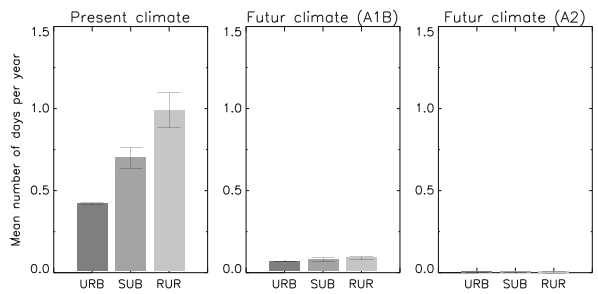

d. Ice days
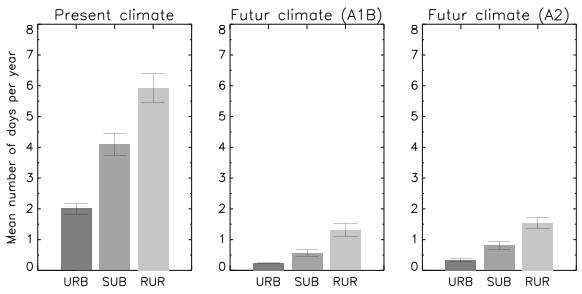

f. Very very hot days
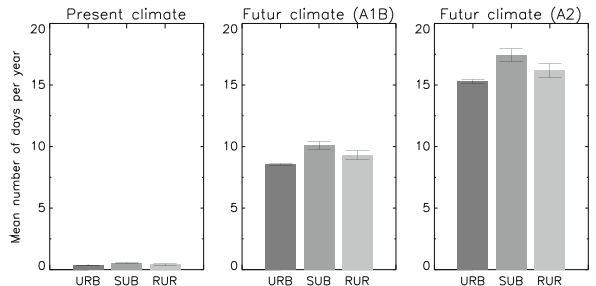

h. Heat-wave warnings
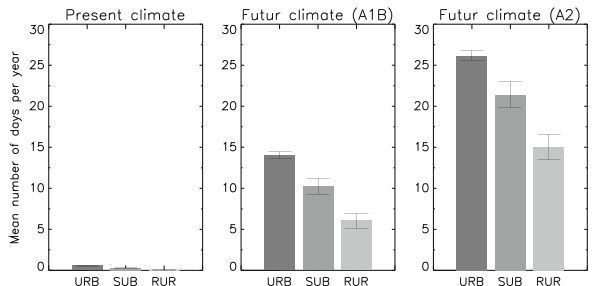

Fig. 4 Mean number of cold days $\left(T_{N} \leq-5^{\circ} \mathrm{C}\right)$, very cold days $\left(T_{N} \leq-10^{\circ} \mathrm{C}\right)$, frost days $\left(T_{N} \leq\right.$ $\left.0^{\circ} \mathrm{C}\right)$, ice days $\left(T_{X} \leq 0^{\circ} \mathrm{C}\right)$, very hot days $\left(T_{X} \geq 30^{\circ} \mathrm{C}\right)$, very very hot days $\left(T_{X} \geq 35^{\circ} \mathrm{C}\right)$, tropical nights $\left(T_{N} \geq 20^{\circ} \mathrm{C}\right)$, and heat-wave warnings per year for urban, suburban, and rural areas-referred to as URB, SUB, and RUR, respectively-over present (control period) and future climates (A1B and A2 scenarios). The black bars represent the standard deviation due to the spatial variability of the indice for each land-cover type

by using ten climate projections coming from the ENSEMBLES European project and the internal database of Météo-France (Beaulant et al. 2012). Nine of the ten projections confirm that the warming is more important in summer than in winter, and more sharp for $T_{X}\left(+3.63^{\circ} \mathrm{C}\right.$ in average and a standard deviation of $\left.1.08^{\circ} \mathrm{C}\right)$ than for $T_{N}\left(+2.92^{\circ} \mathrm{C}\right.$ in average and a standard deviation of $\left.0.70^{\circ} \mathrm{C}\right)$.

In the present case, the results also display that the warming trend is less marked in the urbanized areas, and more particularly at daytime $\left(+3.4\right.$ and $+4.7^{\circ} \mathrm{C}$ for night 
and day, respectively). The high temperatures simulated in rural and suburban areas are probably linked with a soil dryness during summer because the analysis of the ARPEGE projections indicates a significant decrease between future and present climates both in cumulative precipitation ( -16 and $-20 \%$ according to A1B and A2 scenarios) and in number of rainy days $(-23$ and $-33 \%)$. These trends lead to a decrease in soil water contents associated with a strong increase in soil temperature of $+4.5^{\circ} \mathrm{C}\left(+5.8^{\circ} \mathrm{C}\right)$ for $\mathrm{A} 1 \mathrm{~B}(\mathrm{~A} 2)$ scenario and a decrease in evaporation of $28 \%$ $(37 \%)$.

Climate indices for summertime temperature are hot days, very hot days, and very very hot days (days with $T_{X} \geq 25,30$, and $35^{\circ} \mathrm{C}$, respectively), tropical nights $\left(T_{N} \geq 20^{\circ} \mathrm{C}\right)$, and heat-wave warnings. The heat-wave warning is based on biometeorological indices which are computed by averaging maximum and minimum temperature over three consecutive days considered as the minimum duration of a heat wave. Météo-France issues a heat-wave warning when both thresholds on minimum and maximum biometeorological indices $\left(21\right.$ and $31^{\circ} \mathrm{C}$ for Paris region, respectively) are exceeded.

As expected with the increase of summertime temperature, hot (not shown), very hot, and very very hot days are more frequent in the future climate (Fig. $4 \mathrm{e}$ and f). From 5 to 6 very hot days per year depending on the areas, it reaches 29 (42) very hot days per year in urban and rural areas, and 33 (47) very hot days per year in suburban areas according to A1B (A2) scenario; near zero in present time, the number of very very hot days per year reaches 8 (15) in urban areas, 10 (17) in suburban areas, and 9 (16) in rural areas according to A1B (A2) scenario. It is interesting to emphasize that these summertime indices increase much more significantly in rural areas than in urbanized areas because of the large soil drying of natural soils. On the other hand, the potential of warming in urban areas is maybe limited due to the high temperatures already observed at these locations in present climate. Finally, it is noted that in both scenarios the number of very hot and very very hot days is more important in suburban areas where the effects of partial urbanization and soil dryness accumulate.

The number of tropical nights per year increases as well (Fig. 4g). It remains much more important in urban areas as a result of nocturnal UHIs: from 6 tropical nights per year in present climate to 35 (50) in future climate according to A1B (A2) scenario. However, the increase in suburban areas-from 2 to 23 (36) - and in rural areas-from 1 to 15 (26) - is significant too.

Heat-wave warnings increase in the same magnitude (Fig. 4h): from less than 1 day of warning per year in present climate (with return periods of about 2, 4, and 20 years for urban, suburban, and rural areas, respectively) to 14 (26) in urban areas, 11 (22) in suburban areas, and 7 (17) days in rural areas according to A1B (A2) scenario. In the same way as for tropical nights, the heat-wave warnings are more numerous in urban areas than in suburban and rural areas showing that the threshold on the minimum biometeorological indice is prevailing, i.e., the minimum 2-m air temperature is the main criterion.

\subsection{Urban heat islands}

The UHIs are calculated as the temperature difference between urban and rural areas by using the daily minimum and maximum 2-m air temperatures simulated by 

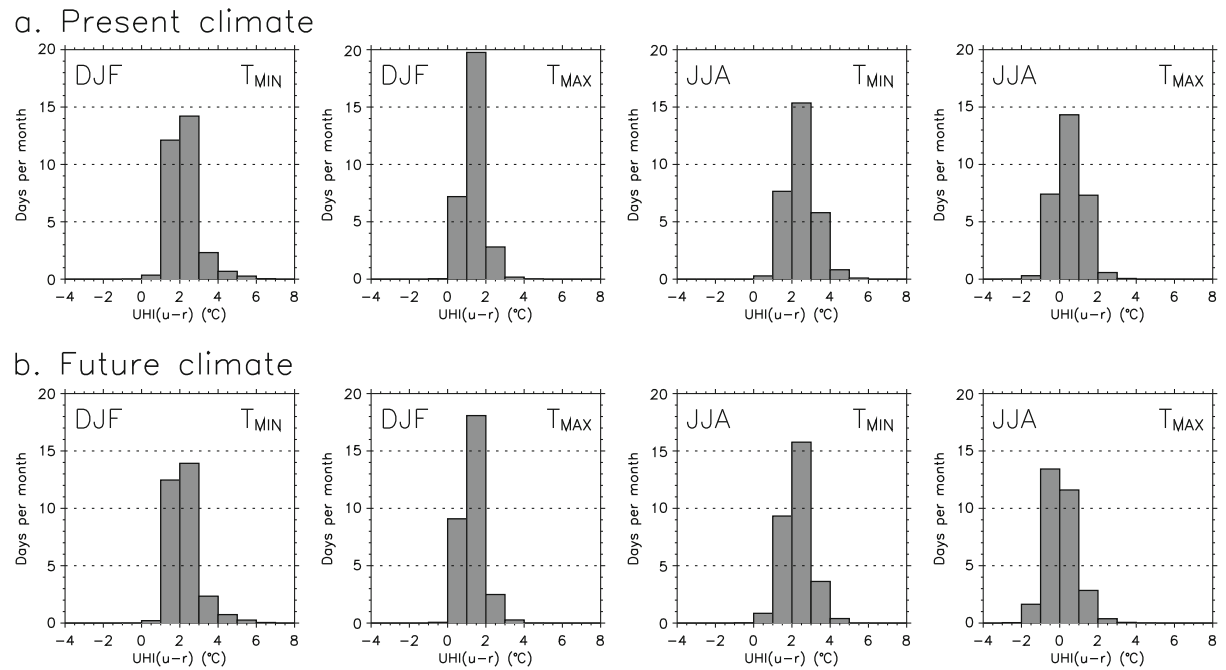

Fig. 5 Distribution of the UHIs by classes of intensity in present (top) and future (bottom) climates for A1B and A2 scenarios. The UHIs are computed independantly for daily minimum and maximum 2-m air temperatures (averaged over urban and rural areas), and for winter (DJF) and summer (JJA)

the model and averaged by cover class and by season. It may be noted that no correction of topographic variability across the study area is applied for the calculation of UHIs. As a result, these UHIs may be influenced by the local topography-especially at night-in addition to the urban effects. However, the topographic variability is low. In average, the elevation of rural areas is $50 \mathrm{~m}$ higher than that of urban areas. One can therefore expect that the nocturnal UHIs are a little underestimated. The distribution of UHIs by classes of intensity is presented in Fig. 5. For future climate, the results obtained for $\mathrm{A} 1 \mathrm{~B}$ and $\mathrm{A} 2$ scenarios are combined.

In present climate, the UHIs are always positive during winter with values varying between 0 and $6^{\circ} \mathrm{C}$ for $T_{N}$ and between 0 and $4{ }^{\circ} \mathrm{C}$ for $T_{X}$. The same range is detected in future climate. The distribution is quite similar to that of present climate for nocturnal UHIs but different for those of daytime. In this case, the frequency of the UHIs greater than $1{ }^{\circ} \mathrm{C}$ decreases of $6 \%$ to the benefit of very weak UHIs and even some cases of negative UHIs. The differences in the distributions are more important in summer. In present climate, the UHIs vary between 0 and $6^{\circ} \mathrm{C}$ for $T_{N}$ and between -2 and $4^{\circ} \mathrm{C}$ for $T_{X}$. The frequency of the strong UHIs decreases significantly both during nighttime and daytime: $74 \%$ of nocturnal UHIs are at least of $2{ }^{\circ} \mathrm{C}$ in present climate against $66 \%$ in future climate; besides, at daytime $74 \%$ of UHIs are positive in present climate against $50 \%$ only in future climate. These results are directly connected to the high temperatures simulated in rural areas correlated with soil drying (see Section 5.3).

\section{Energy consumption}

A large impact of future climate change is expected for the seasonal distribution of energy consumption in cities. A simple way to evaluate this impact is to compute the 
heating and cooling degree days over the periods of present and future climates. One heating degree day (HDD) corresponds to one degree of departure below a conventional minimum temperature $T_{\text {std }_{N}}$; one cooling degree day (CDD) corresponds to one degree of departure above a conventional maximum temperature $T_{\text {std }_{X}}$. According to the French standards (Porcher 1993), $T_{\operatorname{std}_{N}}$ and $T_{\operatorname{std}_{X}}$ are prescribed to 18 and $24^{\circ} \mathrm{C}$ day, respectively. They represent the thresholds below or above which the indoor thermal comfort is not maintained without domestic heating or air-conditioning.

In this study, annual HDDs and CDDs are calculated for present and future climates (averaged over 1971-2006 and 2072-2098, respectively) and presented in Table 2. For the evaluation of the orders of magnitude obtained by the simulation over the control period, HDDs and CDDs are also calculated by using the timeseries of 2-m air temperature recorded by the operational meteorological station of Montsouris located in the city-center of Paris. The degree days averaged over the period $1971-2006$ are 2,352 and $17^{\circ} \mathrm{C}$ day for HDDs and CDDs, respectively. These results highlight the significant needs in domestic heating during winter for the current climate, whereas the air-conditioning needs remain rather weak. They are in good agreement with the simulated values of CDD and HDD which reach 2,330 and $14^{\circ} \mathrm{C}$ day, respectively.

Because of the increase of wintertime temperature in future climate, HDDs decrease of about $30 \%$, from 2,330 to $1,622^{\circ} \mathrm{C}$ day in average over both scenarios in urban areas and from 2,493 to $1,838^{\circ} \mathrm{C}$ day in suburban areas where the needs in heating are a bit higher. Inversely, CDDs considerably increase in proportion but the magnitude remains much smaller than the decrease of HDDs, e.g., CDDs increase by $+153^{\circ} \mathrm{C}$ day in urban areas whereas HDDs decrease of $-708^{\circ} \mathrm{C}$ day. As a result, the model simulates a mean decrease of the degree days of $-555^{\circ} \mathrm{C}$ day in urban areas and $-512^{\circ} \mathrm{C}$ day in suburban areas, with differences between $\mathrm{A} 1 \mathrm{~B}$ and $\mathrm{A} 2$ scenarios not exceeding $\pm 7 \%$.

Table 2 Heating and cooling degree days per year (Unit: ${ }^{\circ} \mathrm{C}$ day) averaged for urban and suburban areas over present ( 36 years) and future (27 years) climates

\begin{tabular}{|c|c|c|c|c|}
\hline & \multicolumn{2}{|l|}{ Urban } & \multicolumn{2}{|c|}{ Suburban } \\
\hline & HDD & $\mathrm{CDD}$ & HDD & CDD \\
\hline \multicolumn{5}{|l|}{ Obs } \\
\hline (1971-2006) & 2,352 & 17 & - & - \\
\hline \multicolumn{5}{|l|}{ Present } \\
\hline (1971-2006) & 2,330 & 14 & 2,493 & 10 \\
\hline \multicolumn{5}{|l|}{ Future } \\
\hline \multicolumn{5}{|l|}{ A1B } \\
\hline (2072-2098) & 1,691 & 127 & 1,911 & 115 \\
\hline \multicolumn{5}{|l|}{ A2 } \\
\hline (2072-2098) & 1,554 & 207 & 1,765 & 191 \\
\hline \multicolumn{5}{|l|}{ Future-present } \\
\hline A1B & -639 & +113 & -582 & +105 \\
\hline A2 & -776 & +193 & -728 & +181 \\
\hline
\end{tabular}

The first line of the table presents HDD and CDD calculated for the meteorological station of Montsouris (Paris city-center) over present climate 


\section{Conclusion}

The impact of climate change on the regional-scale climate of the large Paris area at the end of the 21 st century is analyzed by conducting long-term offline numerical integrations. Thanks to a land surface modeling system including a specific urban parameterization with a $1-\mathrm{km}$ spatial resolution, the emphasis is put on the study of the interactions between local effects of global change and urban processes such as UHI.

In winter, the temperature significantly increases in future climate by about +2.0 and $+2.4^{\circ} \mathrm{C}$ in average over both scenarios for minimum and maximum daily temperatures, respectively, between 1971-2006 and 2072-2098. This trend is particularly marked in the most urbanized areas where the number of cold days (with minimum temperature lower than $-5^{\circ} \mathrm{C}$ ) becomes null, as well as the number of ice days (maximum temperature lower than $0^{\circ} \mathrm{C}$ ). In summer, the evolution of temperature is more important than in winter $\left(+3.5\right.$ and $+5.0^{\circ} \mathrm{C}$ in average over both scenarios for the minimum and maximum daily temperatures). Contrary to the expected results, the warming trend is more marked in rural areas than in urbanized areas because of the drying of natural soils (which is in agreement with the increase duration of drought events found by Planton et al. 2008). As a result, a substantial decrease of the strong UHIs (greater than $2^{\circ} \mathrm{C}$ ) is noted at nighttime, and numerous events with negative UHIs appear at daytime. It is also emphasized that the extremes in temperature are the most important in suburban areas where the effects of partial urbanization and soil dryness accumulate. On the one hand, the urban geometry is less dense than that of the city center, which reduces the shadow effects and promotes warming of the air in the street-canyon (as already shown by Lemonsu et al. 2009, for Oklahoma City, US). In addition, the dryness of natural soils severely limits evaporation, which tends to strengthen the sensible heat flux. This process frequently drives the occurrence of cool islands during daytime for cities surrounded by arid environments, e.g. Beer Sheba, Israel (Saaroni and Ziv 2010).

Finally, the energy demand issue is tackled through the analysis of heating and cooling degree days. The comparison of HDDs and CDDs calculated in present and future climates indicates a $30 \%$ decrease of the needs in heating during winter, and inversely an increase of the needs in air-conditioning to maintain thermal comfort during summer. The order of magnitudes shows, however, that the increase in CDDs remains smaller than the decrease in HDDs, even if this strongly depends on the choice of the conventional temperatures used for the calculation of the degree days.

This work proposes an original methodology in order to analyze the impact of global climate change on the Paris region local climate. More particularly, the integration of a specific urban canopy model (TEB) enables to focus on streetlevel micro-climate that is perceived by inhabitants. The results of the local climate projections display consistent trends whatever the emission scenario (A1B or A2). However, we plan in a next stage to consider a larger set of climatic projections provided by different global or regional climate models in order to quantify more accurately the model errors and the result dispersion. Besides, we are developing a downscaling technique more appropriate to the urban issue that aims at including in the atmospheric forcing the urban heat island signature.

Acknowledgements The authors would like to thank Dr. M. Colombert and the urban planning agency of Paris (APUR) who provided the descriptive parameters of the city. They also acknowledge 
Dr. E. Martin and Dr. P. Quintana-Seguí who made possible the use of the climatic forcing coming from the RExHySS project. The EPICEA project is funded by the city of Paris within the framework of its Climate Plan.

Open Access This article is distributed under the terms of the Creative Commons Attribution License which permits any use, distribution, and reproduction in any medium, provided the original author(s) and the source are credited.

\section{References}

Alexander LV, Zhang X, Peterson TC, Caesar J, Gleason B, Klein Tank AMG, Haylock M, Collins D, Trewin B, Rahimzadeh F, Tagipour A, Ambenje P, Rupa Kumar K, Revadekar J, Griffiths G (2006) Global observed changes in daily climate extremes of temperature and pricepitation. J Geophys Res 111:D05109. doi:10.1029/2005JD006290

Amato AD, Ruth M, Kirshen P, Horwitz J (2005) Regional energy demand responses to climate change: methodology and application to the Commonwealth of Massachusetts. Clim Change 71(1-2):175-201

Athanassiadou M, Baker J, Carruthers D, Collins W, Girnary S, Hassell D, Hort M, Johnson C, Johnson K, Jones R, Thomson D, Trought N, Witham C (2010) An assessment of the impact of climate change on air quality at two UK sites. Atmos Environ 44:1877-1886

Beaulant A-L, Lemonsu A, Somot S, Masson V (2012) Future heat waves over Paris metropolitan area. National Security and Human Health Implications of Climate Change, NATO Science for Peace and Security Series C: Environmental Security, pp 135-145. doi:10.1007/94007-2430-3_12

Déqué M (2005) Coauthors Impact des changements anthropiques sur la fréquence des phénomènes extrêmes de vent, de température et de précipitations. IMFREX Final Report. Available at http://medias.obs-mip.fr/gicc/docgicc/public/projets/apr02/projet4/final-4-02.doc

Déqué M (2007) Frequency of precipitation and temperature extremes over France in an anthropogenic scenario: model results and statistical correction according to observed values. Glob Planet Change 57(1-2):16-26

Déqué M (2009) Méthode de désagrégation quantile/quantile conditionnelle. Annex V1a of the RExHySS Final Report. Available at http://www.sisyphe.upmc.fr/ agnes/rexhyss/documents_ rapport.php

Desplat J, Salagnac J-L, Kounkou-Arnaud R, Lemonsu A, Colombert M, Lauffenburger M, Masson V (2009) EPICEA project [2008-2010]: multidisciplinary study of the impacts of climate change on the scale of Paris. In: 7th international conference on urban climate, Yokohama, Japan

Ducharne A, Habets F, Déqué M, Evaux L, Hachour A, Lepaillier A, Lepelletier, T, Martin E, Oudin L, Pagé C, Ribstein P, Sauquet E, Thiéry D, Terray L, Viennot P, Boé J, Bourqui M, Crespi O, Gascoin S, Rieu J (2009) Impact du changement climatique sur les Ressources en eau et les Extrêmes Hydrologiques dans les bassins de la Seine et la Somme. RExHySS Final Report, GICC Program, p 62. Available at http://www.sisyphe.upmc.fr/ agnes/rexhyss/documents_rapport.php

Durand Y, Brun E, Merindol L, Guyomarc'h G, Lesaffre B, Martin E (1993) A meteorological estimation of relevant parameters for snow models. Ann Glaciol 18:65-71

Durand Y, Giraud G, Brun E, Merindol L, Martin E (1999) A computer-based system simulating snowpack structure as a tool for regional avalanche forecasting. J Glaciol 45:469-484

Franco G, Sanstad AH (2008) Climate change and electricity demand in California. Clim Change 87:139-151

Früh B, Becker P, Deutschlnder T, Hessel JD, Kossmann M, Mieskes I, Namyslo J, Roos M, Sievers U, Steigerwald T, Turau H, Wienert U (2011) Estimation of climate change impacts on the urban heat load using an urban climate model and regional climate projections. J Appl Meteorol Climatol 50:167-184

Fujibe F (2011) Urban warming in Japanese cities and its relation to climate change monitoring. Int J Climate 31(2):162-173

Gaffin SR, Rosenzweig C, Khanbilvardi R, Parshall L, Mahani S, Glickman H, Goldberg R, Blake R, Slosberg RB, Hillel D (2008) Variations in New York City's urban heat island strength over time and space. Theor Appl Climatol 94:1-11 
García Cueto RO, Tejeda Martínez A, Jáuregui Ostos E (2010) Heat waves and heat days in an arid city in the northwest of Mexico: current trends and in climate change scenarios. Int J Biometeorol 54(4):335-345

Gibelin AL, Déqué M (2003) Anthropogenic climate change over the Mediterranean region simulated by a global variable resolution model. Clim Dyn 20:327-339

Hallegatte S, Hourcade J-C, Ambrosi P (2007) Using climate analogues for assessing climate change economic impacts in urban areas. Clim Change 82(1):47-60

Heymann Y, Coauthors (1993) CORINE land cover: technical guide. Environment, nuclear safety and civil protection series, Commission of the European Communities, Office for Official Publication of the European Communities, Luxembourg, p 144

IPCC (2000) Special report on emissions scenarios. Cambridge University Press, UK, p 570

IPCC (2007) Climate change 2007: synthesis report, core writing team. In: Pachauri RK, Reisinger A (eds) IPCC, Geneva, Switzerland, p 104

Jones PD, Groisman PYA, Coughlan M, Plummer N, Wang W-C, Karlparallel TR (1990) Assessment of urbanization effects in time series of surface air temperature over land. Nature 347:169172

Klein Tank AMG, Können GP (2003) Trends in indices of daily temperature and precipitation extremes in Europe, 1946-99. J Clim 16:3665-3680

Klein Tank AMG, Zwiers FW (2009) Guidelines on analysis of extremes in a changing climate in support of informed decisions for adaptation. WMO/TD-No. 1500, p 55

Lemonsu A, Bélair S, Mailhot J (2009) The new Canadian urban modelling system: evaluation for two cases from the Joint Urban 2003 Oklahoma City experiment. Boundary-Layer Meteorol 133(1):47-70

Masson V (2000) A physically-based scheme for the urban energy budget in atmospheric models. Boundary-Layer Meteorol 94:357-397

Noilhan J, Planton S (1989) A simple parameterization of land surface processes for meteorological models. Mon Weather Rev 117:536-549

O'Hara JK, Georgakakos KP (2008) Quantifying the urban water supply impacts of climate change. Water Resour Manag 22(10):1477-1497

Planton S, Déqué M, Chauvin F, Terray L (2008) Expected impacts of climate change on extreme climate events. C R Geoscience 340:564-574

Porcher G (1993) Cours de climatisation: bases du calcul des installations de climatisation. Les Editions parisiennes, $\mathrm{p} 317$

Rosenzweig C, Solecki WD (2001) Climate change and a global city - learning from New York. Environment 43(3):2-12

Saaroni H, Ziv B (2010) Estimating the urban heat island contribution to urban and rural air temperature differences over complex terrain: application to an arid city. J Appl Meteorol Climatol 49:2159-2166

Salgado R, Le Moigne P (2010) Coupling of the FLake model to the surfex externalized surface model. Boreal Environ Res 15:231-244

Van den Besselaar EJM, Klein Tank AMG, Van der Schrier G (2010) Influence of circulation types on temperature extremes in Europe. Theor Appl Climatol 99:431-439. doi:10.1007/s00704009-0153-6

Wilby RL (2003) Past and projected trends in London's urban heat island. Weather 58(7):251-260 